\title{
Role of endoscopic ultrasound-guided fine needle aspiration in the diagnosis of mass lesions
}

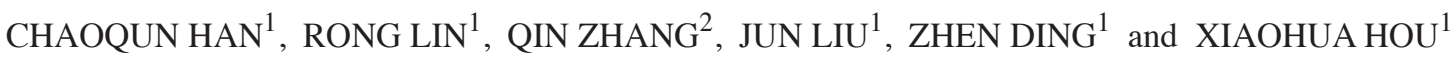 \\ Departments of ${ }^{1}$ Gastroenterology and ${ }^{2}$ Pathology, Union Hospital, Tongji Medical College, \\ Huazhong University of Science and Technology, Wuhan, Hubei 430022, P.R. China
}

Received January 4, 2015; Accepted March 30, 2016

DOI: $10.3892 /$ etm.2016.3433

\begin{abstract}
Endoscopic ultrasound-guided fine needle aspiration (EUS-FNA) is an accurate technique for sampling the pancreas and mediastinum; however, limited data are available for other mass lesions. The aim of this study was to explore the value of EUS-FNA in the differential diagnosis of all mass lesions. Data from patients who underwent EUS-FNA for the diagnosis of mass lesions, including pancreatic, mediastinal, celiac and retroperitoneal lesions were retrospectively analyzed. The accuracy was calculated by comparing the results of FNA with the results of pathological examination or follow-up surveillances in non-operated cases. A total of 150 cases were included. The location of the mass varied from the pancreas $(n=62)$ to the mediastinum $(n=29)$, gastrointestinal tract $(n=36)$, celiac cavity and retroperitoneum $(n=23)$. The sensitivity and Youden's index of EUS-FNA in the diagnosis of all lesions were $92.97 \%$ and 0.93 respectively. The accuracy of diagnosis of pancreatic, mediastinal, gastrointestinal, celiac and retroperitoneal lesions was 85.48, 89.66, 83.33 and 78.23\%, respectively. Masses were categorized into parenchymal organs $(n=66)$, luminal organs $(n=36)$ and enlarged lymph nodes $(n=33)$. Lesions in parenchymal organs were likely to be bigger than those in luminal organs $(\mathrm{P}=0.03)$ and enlarged lymph nodes $(\mathrm{P}=0.01)$. For solid and cystic masses, which constituted 63.3 and $14.7 \%$ of the total masses, no significant difference in diagnostic accuracy was observed $(\mathrm{P}=0.56)$; however, lesion sizes were significantly different between these two groups $(\mathrm{P}=0.04)$ and the majority of cystic masses were identified in women $(\mathrm{P}=0.03)$. Malignant lesions were more common in older $(\mathrm{P}=0.01)$ and male $(\mathrm{P}=0.03)$ patients. In conclusion, EUS-FNA is an effective tool in the diagnosis
\end{abstract}

Correspondence to: Professor Zhen Ding, Department of Gastroenterology, Union Hospital, Tongji Medical College, Huazhong University of Science and Technology, 1277 Jiefang Avenue, Wuhan, Hubei 430022, P.R. China E-mail: docd720@126.com

Key words: endoscopic ultrasonography, fine needle, mass lesion, diagnosis of unexplained mass lesions; it influences the management of patients by enabling the appropriate treatment to be identified.

\section{Introduction}

Despite advances in diagnostic imaging techniques and the use of tumor markers, even with the development of spiral computed tomography (CT) and positron emission tomography (PET), the differentiation of pancreatic cancer and focal pancreatitis or other mass lesions, such as retroperitoneal or pelvic lesions remains problematic (1-3). Since the first report of endoscopic ultrasound (EUS)-fine needle aspiration (FNA) of the pancreas by Vilmann et al (4) in 1992, EUS-FNA has been considered as a standard method for the diagnosis of mass lesions in the pancreas because it is an effective and accurate procedure with a low complication rate (5-8) and, moreover, it provides cytological or pathological confirmation of benign or malignant disease. It has also been recognized as a minimally invasive and maximum accurate diagnostic procedure $(7,9)$. Furthermore, this least invasive procedure is often suitable for use in the endoscopic procurement of tissue from patients with unresectable tumors (10).

While EUS-FNA has been increasingly used as a valuable diagnostic modality for mass lesions, the majority of studies have collectively investigated primary pancreatic and mediastinal lesions, including focal pancreatitis, pancreatic neuroendocrine neoplasms and mediastinal lymphadenopathy $(5,10-15)$, the accuracy of which has previously been presented in the form of a meta-analysis (16-18). However, very few studies have examined other types of mass lesions, such as those affecting the enterocoelia or retroperitoneum, due to the anatomical structural challenges $(19,20)$. Therefore, the aim of the present study was to evaluate the diagnostic accuracy of EUS-FNA and to investigate the associations of diagnostic findings with various types of mass lesions.

\section{Materials and methods}

Patients. A total of 150 patients presenting to the Department of Gastroenterology, Union Hospital, Tongji Medical College (Wuhan, China) and undergoing EUS-FNA of mass lesions over a 4-year study period, from June 2010 to March 2014, were enrolled in the study. Suspicions of mass lesions were based on radiological findings or abdominal imaging such as 
magnetic resonance imaging (MRI), abdominal CT or transabdominal ultrasound. Targets included gastrointestinal and extra-gastrointestinal mass lesions and peri-gastrointestinal lymph nodes. Patients were excluded if they had a blood coagulation disorder or had used non-steroidal anti-inflammatory drugs or other anticoagulant drugs within 14 days of the EUS-FNA. The study was approved by the Ethics Committee of Tongji Medical College, Huazhong University of Science and Technology (Wuhan, China). All patients provided signed informed consent.

EUS technique. EUS was performed using an Olympus Ultrasound Processor (EU-ME1) with a UCT-240 linear endoscope (Olympus America, Inc., Center Valley, PA, USA). FNA was operated under EUS guidance with 0,5 or $10 \mathrm{ml}$ of suction applied during aspiration with either a 22-gauge or 19-gauge needle (22G Endocoil or 19G Echotip; Cook Endoscopy, Winston-Salem, NC, USA). Needle passes were processed about 1 to 6 times until the operator considered that sample adequacy was achieved. Samples were prepared by EUS assistants trained by cytology technicians and sent to the pathology department for evaluation. EUS-FNA was performed by two well-trained ( $>1,500$ EUS procedures) endoscopists.

Data collection. Data collected included patient demographics (gender, age and mass lesion location) and procedure details (tumor characteristics and number of needle passes). Post-procedure complications were defined as any symptoms requiring emergency department evaluation, including bleeding, pneumothorax, perforation, pancreatitis and other severe complications.

A diagnostic result was defined by cytological or histological findings as EUS-FNA biopsy positive for tumor cells of any type, acid-fast bacillus, mesenchymoma or leiomyoma. Cytological or histological findings of negative for atypical cells (inflammatory cells, phagocytes or epithelial cells), suspicious and not obtaining adequate sample were considered non-diagnostic. All the EUS-FNA results were compared with the gold standard of surgical findings or follow-up examinations in non-operated cases over a minimum period of 6 months and a final diagnosis was determined.

Statistical analysis. Performance characteristics including sensitivity, specificity, positive predictive value (PPV), negative predictive value (NPV) and overall diagnostic accuracy were calculated. Continuous variable results were reported as means with/without standard deviation (SD). Dichotomous variables are shown as percentages with or without $95 \%$ confidence intervals (CIs). The $\chi^{2}$ test was used for comparisons of rates, and means between two groups or three groups were assessed with independent-samples t-tests and one-way analysis of variance, respectively. Statistical analyses were performed with SPSS software, version 19.0 (IBM SPSS, Armonk, NY, USA). P<0.05 was considered to indicate a statistically significant difference.

\section{Results}

General characteristics. Data for 150 patients (57 female and 93 male) undergoing EUS-FNA evaluation for mass lesions were entered into a designed database. Study patients were relatively old (mean age, 54.3 years, range, 21-80 years). The mean lesion size was $3.5 \pm 1.9 \mathrm{~cm}$ (range, $0.4-10 \mathrm{~cm}$ ). The numbers of pancreatic, mediastinal, gastrointestinal, celiac and retroperitoneal lesions were 62 (41.3\%), 29 (19.3\%), $36(24.0 \%)$ and $23(15.4 \%)$ cases, respectively. The number of passes performed per patient in this study was between 1 and 6 with a mean of 2.4. The basic characteristics and details of all cases (location and size of the lesions, as well as the results of EUS-FNA) are listed in Table I.

EUS-FNA findings. Adequate specimens for pathological assessment or cytological examination were obtained for 136 patients (90.7\%) and $23(15.3 \%)$ cases had indeterminate results (non-diagnostic, atypical or suspicious). The EUS-FNA diagnoses were as follows: 87 (58.0\%) had malignant cytology, $3(2 \%)$ were suspicious for neoplasia, $6(4.0 \%)$ had atypical cells and $40(26.7 \%)$ were found to be benign. There were 14 cases $(9.3 \%)$ where the FNA was non-diagnostic (an inadequate sample was obtained). Of the 23 patients with indeterminate results, 2 patients had surgical pathology and in the remaining 21 cases, the diagnosis was based on clinical follow-up examination. There were no false positive cases or false negative cytological cases. The EUS-FNA findings are detailed in Table II.

Diagnostic value of EUS-FNA. The overall diagnostic rate of EUS-FNA for all lesions was $84.67 \%$ (127/150; 95\% CI, 78.90-90.44\%), and the sensitivity, specificity, PPV, NPV, accuracy and Youden's index for lesions at various locations are presented in Table III. The accuracy for mediastinal lesions was the highest (89.66\%); however, celiac and retroperitoneal lesions had a diagnostic accuracy of only $78.2 \%$, which may be due to the presence of vital interferential structures.

The masses were categorized into those associated with parenchymal organs $(n=66)$, luminal organs $(n=36)$ and enlarged lymph nodes $(n=33)$. Parenchymal organs were more likely to have a larger lesion diameter compared with luminal organs $(\mathrm{P}=0.03)$ and enlarged lymph nodes $(\mathrm{P}=0.01)$. Otherwise, age, number of passes, sensitivity and accuracy were similar among the three categories of masses $(\mathrm{P}>0.05$; Table IV). The accuracy of EUS-FNA in the diagnosis of parenchymal organs, luminal organs and enlarged lymph nodes was $86.36,83.33$ and $87.88 \%$ respectively.

Moreover, 95 (63.3\%) lesions were considered as solid masses and $22(14.7 \%)$ as cystic masses. There was no statistically significant difference in patient age $(\mathrm{P}=0.81)$ and diagnostic sensitivity $(\mathrm{P}=1.00)$ between the these two types of mass. The accuracy of diagnosis of solid masses was higher than that of cystic masses (85.26 vs. $77.27 \%$ ), although with no statistical significance $(\mathrm{P}=0.56)$. Furthermore, no correlation was observed with respect to the number of passes $(\mathrm{P}=0.38)$. However, lesion size $(\mathrm{P}=0.04)$ and gender $(\mathrm{P}=0.03)$ had a statistically significant difference between these two groups (Table V). Cystic masses were found to have a larger diameter compared with solid masses $(\mathrm{P}<0.05)$. The majority of solid masses were identified in men and cystic masses in women.

Masses were also categorized into malignant and benign masses. The final diagnosis, which was confirmed by the pathological examination or follow-up surveillances, was malignant in 100 cases and benign disease in 50 cases. The most frequently 
Table I. Basic information of lesion characteristics for all 150 patients, EUS-FNA results and final diagnosis.

\begin{tabular}{|c|c|c|c|c|c|c|c|}
\hline \multirow{2}{*}{$\begin{array}{l}\text { Lesion } \\
\text { location }\end{array}$} & \multirow[b]{2}{*}{ Final diagnosis } & \multirow{2}{*}{$\begin{array}{l}\text { Gender, } \\
\text { male/female }\end{array}$} & \multirow{2}{*}{$\begin{array}{l}\text { Mean } \\
\text { age } \\
\text { (years) }\end{array}$} & \multirow{2}{*}{$\begin{array}{l}\text { Mean } \\
\text { size, } \\
(\mathrm{cm})\end{array}$} & \multirow{2}{*}{$\begin{array}{l}\text { Mean } \\
\text { no of. } \\
\text { passes }\end{array}$} & \multicolumn{2}{|c|}{ EUS-FNA results } \\
\hline & & & & & & Positive & Negative \\
\hline \multirow[t]{10}{*}{ Pancreas $(n=62)$} & Pancreatic cancer & $25 / 7$ & 58.28 & 3.19 & 2.00 & 26 & 6 \\
\hline & Chronic pancreatitis & $1 / 2$ & 51.33 & 2.34 & 2.00 & 3 & 0 \\
\hline & Autoimmune pancreatitis & $2 / 1$ & 58.00 & 3.60 & 2.00 & 1 & 2 \\
\hline & Solid pseudopapillary tumor & $1 / 1$ & 44.00 & 5.50 & 4.00 & 1 & 1 \\
\hline & Pancreatic neuroendocrine neoplasm & $2 / 1$ & 49.00 & 4.46 & 2.00 & 3 & 0 \\
\hline & Pancreatic tuberculosis & $1 / 1$ & 32.50 & 4.55 & 3.00 & 2 & 0 \\
\hline & Pancreatic pseudocyst & $6 / 2$ & 50.38 & 5.63 & 2.00 & 8 & 0 \\
\hline & True pancreatitis cyst & $1 / 2$ & 51.33 & 3.13 & 2.00 & 3 & 0 \\
\hline & Pancreatic cystadenoma & $1 / 5$ & 56.67 & 3.82 & 2.00 & 6 & 0 \\
\hline & Total & $40 / 22$ & 54.68 & 3.73 & 2.63 & 53 & 9 \\
\hline \multirow[t]{8}{*}{ Mediastinum $(n=29)$} & $\begin{array}{l}\text { Mediastinal lymph node metastasis } \\
\text { of lung cancer }\end{array}$ & $5 / 3$ & 56.00 & 3.60 & 2.14 & 8 & 0 \\
\hline & Mediastinal tumor & $5 / 0$ & 61.80 & 4.40 & 2.60 & 5 & 0 \\
\hline & Lymphoma & $2 / 1$ & 65.00 & 2.33 & 3.00 & 2 & 1 \\
\hline & Tuberculosis of mediastinal lymph node & $3 / 1$ & 35.25 & 2.86 & 2.25 & 4 & 0 \\
\hline & Phlogosis of mediastinal lymph node & $3 / 3$ & 54.83 & 2.28 & 2.60 & 4 & 2 \\
\hline & Sarcoidosis & $0 / 2$ & 52.50 & 2.95 & 3.00 & 2 & 0 \\
\hline & Nerve sheath tumors & $0 / 1$ & 59.00 & 3.00 & 3.00 & 1 & 0 \\
\hline & Total & $18 / 11$ & 54.69 & 2.98 & 2.46 & 26 & 3 \\
\hline \multirow[t]{11}{*}{$\begin{array}{l}\text { Gastrointestinal } \\
\text { tract }(n=36)\end{array}$} & Esophageal cancer & $5 / 0$ & 56.80 & 1.94 & 2.00 & 4 & 1 \\
\hline & Esophageal leiomyoma & $2 / 1$ & 40.66 & 3.25 & 3.00 & 3 & 0 \\
\hline & Esophageal tuberculosis & $1 / 2$ & 43.33 & 1.70 & 3.33 & 2 & 1 \\
\hline & Esophagitis & $0 / 1$ & 59.00 & 2.20 & 2.00 & 1 & 0 \\
\hline & Esophageal cyst & $0 / 1$ & 61.00 & 1.20 & 2.00 & 0 & 1 \\
\hline & $\begin{array}{l}\text { Physiological thickening (esophagus, } \\
\text { stomach and rectum) }\end{array}$ & $4 / 4$ & 53.75 & 1.92 & 2.00 & 8 & 0 \\
\hline & Gastric carcinoma & $3 / 1$ & 55.50 & 2.78 & 3.00 & 3 & 1 \\
\hline & Gastrointestinal stromal tumor & $7 / 0$ & 56.86 & 6.48 & 2.33 & 6 & 1 \\
\hline & Duodenitis & $1 / 0$ & 68.00 & 1.00 & 2.00 & 1 & 0 \\
\hline & Rectal carcinoma & $3 / 0$ & 48.33 & 1.24 & 4.20 & 2 & 1 \\
\hline & Total & $26 / 10$ & 53.31 & 2.78 & 2.61 & 30 & 6 \\
\hline \multirow[t]{12}{*}{$\begin{array}{l}\text { Enterocoelia and } \\
\text { retroperitoneum }(n=23)\end{array}$} & Lymphoma & $1 / 5$ & 58.67 & 3.50 & 1.67 & 5 & 1 \\
\hline & Peritoneal tuberculosis & $0 / 1$ & 22.00 & 3.50 & 3.00 & 1 & 0 \\
\hline & Celiac cyst & $2 / 2$ & 58.00 & 4.40 & 2.33 & 0 & 4 \\
\hline & Liver cancer & $1 / 1$ & 56.00 & 4.00 & 2.00 & 2 & 0 \\
\hline & Ewing's sarcoma of soft tissue & $0 / 1$ & 33.00 & 7.00 & 2.00 & 1 & 0 \\
\hline & Renal carcinoma & $1 / 0$ & 75.00 & 8.00 & 1.00 & 1 & 0 \\
\hline & Prostatic cancer & $1 / 0$ & 62.00 & 2.50 & 2.00 & 1 & 0 \\
\hline & Pseudomyxoma peritonei & $1 / 0$ & 68.00 & 3.70 & 4.00 & 1 & 0 \\
\hline & Nerve sheath tumors & $0 / 1$ & 65.00 & 4.50 & 2.00 & 1 & 0 \\
\hline & $\begin{array}{l}\text { Celiac lymph node metastasis } \\
\text { of liver cancer }\end{array}$ & $2 / 2$ & 46.00 & 2.25 & 2.00 & 4 & 0 \\
\hline & Omentum metastasis of ovarian cancer & $0 / 1$ & 49.00 & 2.30 & 2.00 & 1 & 0 \\
\hline & Total & $9 / 14$ & 54.52 & 3.95 & 2.13 & 18 & 5 \\
\hline All patients $(n=150)$ & & $93 / 57$ & 54.33 & 3.52 & 2.38 & 127 & 23 \\
\hline
\end{tabular}

Enterocoelia lesions exclude pancreatic and gastrointestinal masses. EUS-FNA, endoscopic ultrasound-fine needle aspiration. 
Table II. EUS-FNA cytological findings and final diagnoses of targeted mass lesions.

\begin{tabular}{|c|c|c|c|c|}
\hline \multirow[b]{2}{*}{ EUS-FNA diagnosis } & \multirow[b]{2}{*}{$\mathrm{N}$} & \multicolumn{2}{|c|}{ Final diagnosis (n) } & \multirow[b]{2}{*}{ Final diagnosis of malignancy type } \\
\hline & & Benign & Malignant & \\
\hline Benign & 40 & 40 & 0 & - \\
\hline Malignant & 87 & 0 & 87 & See Table I \\
\hline Atypical & 6 & 2 & 4 & Pancreatic cancer $(n=3)$ and lymphoma in mediastinum $(n=1)$ \\
\hline Suspicious & 3 & 1 & 2 & Esophageal cancer $(n=1)$ and rectal carcinoma $(n=1)$ \\
\hline Non-diagnostic & 14 & 7 & 7 & $\begin{array}{l}\text { Lymphoma in retroperitoneum }(n=1) \text {, pancreatic cancer }(n=3) \text {, } \\
\text { solid pseudopapillary tumor }(n=1) \text {, gastric carcinoma }(n=1) \text { and } \\
\text { gastrointestinal stromal tumor }(n=1)\end{array}$ \\
\hline Total & 150 & 50 & 100 & \\
\hline
\end{tabular}

EUS-FNA, endoscopic ultrasound-fine needle aspiration.

Table III. Diagnostic accuracy of EUS-FNA evaluated on the basis of surgical findings or follow-up examination.

\begin{tabular}{lccccccccc}
\hline Lesion location & $\begin{array}{c}\text { Lesion } \\
\text { size }(\mathrm{cm})\end{array}$ & $\begin{array}{c}\text { No. of } \\
\text { passes }\end{array}$ & $\begin{array}{c}\text { Sensitivity } \\
(\%)\end{array}$ & $\begin{array}{c}\text { Specificity } \\
(\%)\end{array}$ & $\begin{array}{c}\text { PPV } \\
(\%)\end{array}$ & $\begin{array}{r}\text { NPV } \\
(\%)\end{array}$ & $\begin{array}{c}\text { Accuracy } \\
(\%)\end{array}$ & $\begin{array}{c}\text { Accuracy } \\
(95 \% \text { CI })\end{array}$ & $\begin{array}{c}\text { Youden's } \\
\text { index }\end{array}$ \\
\hline Pancreas & $1.60-8.00$ & $2-6$ & 92.98 & - & 100.00 & 0.00 & 85.48 & $76.71-94.25$ \\
Mediastinum & $1.10-5.00$ & $2-5$ & 96.30 & - & 100.00 & 0.00 & 89.66 & $78.58-100.00$ & - \\
Gastrointestinal & $0.40-7.00$ & $2-6$ & 91.67 & 100.00 & 100.00 & 80.00 & 83.33 & $71.15-95.51$ & 0.92 \\
Celiac or & $0.60-9.60$ & $1-4$ & 90.00 & - & 100.00 & 0.00 & 78.23 & $61.40-95.12$ & - \\
retroperitoneal & & & & & & & & \\
Total & $0.40-9.60$ & $1-6$ & 92.97 & 100.00 & 100.00 & 47.06 & 84.67 & $78.90-90.44$ & 0.93 \\
\hline
\end{tabular}

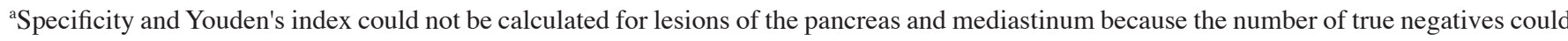
not be determined on the basis of the available data. EUS-FNA, endoscopic ultrasound-fine needle aspiration; PPV, positive predictive value; $\mathrm{NPV}$, negative predictive value; CI, confidence interval.

observed type of malignant mass was pancreatic adenocarcinoma $(n=32 ; 21.3 \%)$. Other types of neoplasia included lymph node metastasis of cancer $(n=12 ; 8.0 \%)$, lymphoma $(n=9 ; 6.0 \%)$ and esophageal tumors $(\mathrm{n}=5 ; 3.3 \%)$. Older patients $(\mathrm{P}=0.01)$ and men $(\mathrm{P}=0.03)$ were more likely to have malignant tumors. No association was found between the FNA accuracy of benign $(80.00 \%)$ and malignant masses $(87.00 \%)$, with a P-value of 0.26 (Table VI). No complications were identified to be associated with the procedure in any of the 150 patients.

\section{Discussion}

Multiple imaging modalities and techniques, including PET, CT, MRI and ultrasound, have been used to evaluate mass lesions; however, small or special lesions pose a diagnostic challenge $(21,22)$. EUS has been demonstrated to be the most significantly advanced procedure, especially for smaller lesions $(<3 \mathrm{~cm})$ (23). However, distinguishing malignant from benign etiologies using EUS can be difficult in certain clinical scenarios, such as chronic pancreatitis and pancreatic neoplasm (1). EUS can only provide the tumor location, size, shape, echo and boundary conditions, and is not able to provide a histological diagnosis. EUS-FNA was introduced to aid in the diagnosis and differentiation between lesion types. Distinguishing adenocarcinoma from local pancreatitis has important implications for prognosis and the method of treatment. A review of the literature concerning EUS-FNA of pancreatic lesions reveals a 78-95\% sensitivity, 75-100\% specificity, 98-100\% PPV, 46-80\% NPV and 78-95\% accuracy (24-26). The present study found that the accuracy of diagnosis of pancreatic lesions was $85.48 \%$ (53/62; 95\% CI 76.71-94.25\%; Table II). However, EUS-guided biopsy was not feasible in all cases (Table I). Nine patients were considered non-diagnostic for pancreatic lesions because the mean number of needle passes was insufficient (2.6 passes) and an adequate sample was not obtained. LeBlanc et al (27) recommend that at least seven passes with a fine needle into pancreatic lesions are required to ensure a high degree of certainty for making a correct diagnosis.

Among the patients in the present study, there was one case that was diagnosed as a mass-forming focal chronic pancreatitis (MFP); yet misdiagnosed as pancreatic cancer before surgery or FNA was performed because pancreatic carcinoma could not be absolutely ruled out under EUS (Figs. 1 and 2). Contrast harmonic echo-EUS may increase the accuracy of detection of malignant lesions in difficult cases (patients with chronic pancreatitis or biliary stents) $(28,29)$ and repeat EUS-FNA is able to provide a conclusive diagnosis in the majority of cases (30). 
Table IV. Patient characteristics for masses of parenchymal organs, luminal organs and enlarged lymph nodes ( $\mathrm{n}=135)$.

\begin{tabular}{|c|c|c|c|c|}
\hline Characteristic & $\begin{array}{c}\text { Parenchymal } \\
\text { organs }(n=66)\end{array}$ & $\begin{array}{c}\text { Luminal } \\
\text { organs }(n=36)\end{array}$ & $\begin{array}{l}\text { Enlarged lymph } \\
\text { nodes }(n=33)\end{array}$ & P-value \\
\hline Male & 43 & 26 & 16 & \multirow{2}{*}{$\mathrm{P}=0.11$} \\
\hline Female & 23 & 10 & 17 & \\
\hline Mean age (years) & 55.14 & 53.31 & 53.15 & $\mathrm{P}=0.65$ \\
\hline Mean lesion size $(\mathrm{cm})$ & 3.78 & 2.78 & 2.92 & $\mathrm{P}^{\mathrm{a}}=0.03 ; \mathrm{P}^{\mathrm{b}}=0.01$ \\
\hline Mean no. of passes & 2.52 & 2.61 & 2.30 & $P=0.70$ \\
\hline Sensitivity (\%) & 93.44 & 91.67 & 96.67 & $P=0.73$ \\
\hline Specificity (\%) & - & 100.00 & - & - \\
\hline PPV (\%) & 100.00 & 100.00 & 100.00 & - \\
\hline NPV (\%) & 0.00 & 80.00 & 0.00 & - \\
\hline Accuracy $(\%)$ & 86.36 & 83.33 & 87.88 & $\mathrm{P}=0.85$ \\
\hline
\end{tabular}

Unlabeled P-values were determined for comparison of the parenchymal organs, luminal organs and enlarged lymph nodes patient groups.

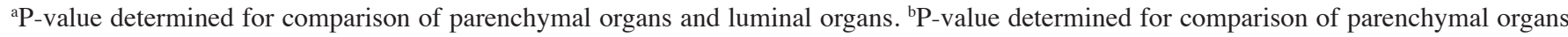
and enlarged lymph nodes. Parenchymal organs include all pancreatic, hepatic, renal and prostatic lesions. Luminal organs comprise all gastrointestinal masses. Diseases of enlarged lymph nodes are constituted by lymphoma, mediastinal lymph node metastasis of lung cancer, celiac lymph node metastasis of liver cancer, sarcoidosis, tuberculosis and phlogosis of mediastinal lymph node. Certain specificity percentages and P-values could not be calculated because the number of true negatives could not be determined on the basis of available data. PPV, positive predictive value; NPV, negative predictive value.

Table V. Comparison of lesions and clinical characteristics in patients with final diagnoses of solid and cystic masses $(\mathrm{n}=150)$.

\begin{tabular}{lccc}
\hline Characteristic & Solid masses $(\mathrm{n}=95)$ & Cystic masses $(\mathrm{n}=22)$ & $\mathrm{P}$-value \\
\hline Male & 67 & 12 & $\mathrm{P}=0.03$ \\
Female & 28 & $54.10 \pm 10.12$ & $\mathrm{P}=0.81$ \\
Age (years), mean \pm SD & $54.79 \pm 12.49$ & $4.20 \pm 2.35$ & $\mathrm{P}=0.04$ \\
Lesion size (cm), mean \pm SD & $3.36 \pm 1.84$ & $2.14 \pm 0.38$ & $\mathrm{P}=0.38$ \\
No. of passes, mean \pm SD & $2.63 \pm 1.41$ & 89.47 & - \\
Sensitivity (\%) & 92.41 & 100.00 & - \\
Specificity (\%) & 100.00 & 0.00 & - \\
PPV $(\%)$ & 100.00 & 77.27 & - \\
NPV (\%) & 57.14 & $\mathrm{P}=0.56$ \\
Overall accuracy $(\%)$ & 85.26 & & - \\
\hline
\end{tabular}

P-values were determined for comparison of solid masses and cystic masses. Cystic masses included pancreatic pseudocyst, true pancreatitis cyst, pancreatic cystadenoma, esophageal cyst and celiac cyst. Solid masses included other lymphadenectasis and cystic diseases. Certain specificity percentages and P-values could not be calculated because the number of true negatives could not be determined on the basis of available data. PPV, positive predictive value; NPV, negative predictive value; SD, standard deviation.

Mediastinal lesions (lymph nodes) may be caused by lymphoma, sarcoidosis or cancer metastasis. As there are various potential types of pathogenesis, blind treatment, such as surgery, may be an unnecessary burden for a patient. EUS-FNA can provide important information for the further management of patients. In the present study, the diameters of mediastinal lesions were $1.1-5.0 \mathrm{~cm}$, and the sensitivity and accuracy of the EUS-FNA were 96.30 and $89.66 \%$, respectively, which is concordant with previously reported data (14). However, the most inadequate specimens for pathological assessment or cytological examination were obtained for celiac and retroperitoneal lesions $(5 / 23,21.74 \%)$. Four cases were celiac cysts. A study conducted by Maleki et al (31) showed that the primary tumor site for such tumors included the colon or rectum, urinary bladder, prostate and ovary, with EUS-FNA exhibiting $87 \%$ sensitivity and a diagnostic accuracy of $90 \%$. The accuracy determined in the present study was lower $(78.23 \%)$. This may be due to the presence of vital interferential structures or the operating distance; power conduction may not have been uniform, and the needle may have failed to penetrate the mass. A further prospective study with a large numbers of patients is necessary to confirm these results. Real-time onsite cytopathology to increase the diagnostic yield and reduce the number of indeterminate or unsatisfactory samples from EUS-FNA may solve this problem (32-34). 
Table VI. Comparison of lesions and basic characteristics in patients with final diagnoses of benign and malignant masses.

\begin{tabular}{lcccccccc}
\hline Lesion type & $\begin{array}{c}\text { Mean age } \\
\text { (years) }\end{array}$ & Male & Female & $\begin{array}{c}\text { Lesion } \\
\text { size }(\mathrm{cm})\end{array}$ & $\begin{array}{c}\text { Mean no. } \\
\text { of passes }\end{array}$ & $\begin{array}{c}\text { Sensitivity } \\
(\%)\end{array}$ & $\begin{array}{c}\text { Specificity } \\
(\%)\end{array}$ & $\begin{array}{c}\text { Accuracy } \\
(\%)\end{array}$ \\
\hline Benign $(\mathrm{n}=50)$ & 50.54 & 25 & 25 & 3.87 & 2.74 & 91.43 & 100.00 & 80.00 \\
Malignant (n=100) & 56.22 & 68 & 32 & 3.20 & 2.35 & 93.55 & - & 87.00 \\
P-value & 0.01 & 0.03 & & 0.08 & 0.16 & 0.98 & - & 0.26 \\
\hline
\end{tabular}

P-values were determined for comparison of benignant and malignant masses. Malignancy included clearly and potentially malignant tumors, such as gastrointestinal stromal tumor. Benign included non-malignant conditions. Certain specificity percentages and P-values could not be calculated because the number of true negatives could not be determined on the basis of available data. PPV, positive predictive value; NPV, negative predictive value.

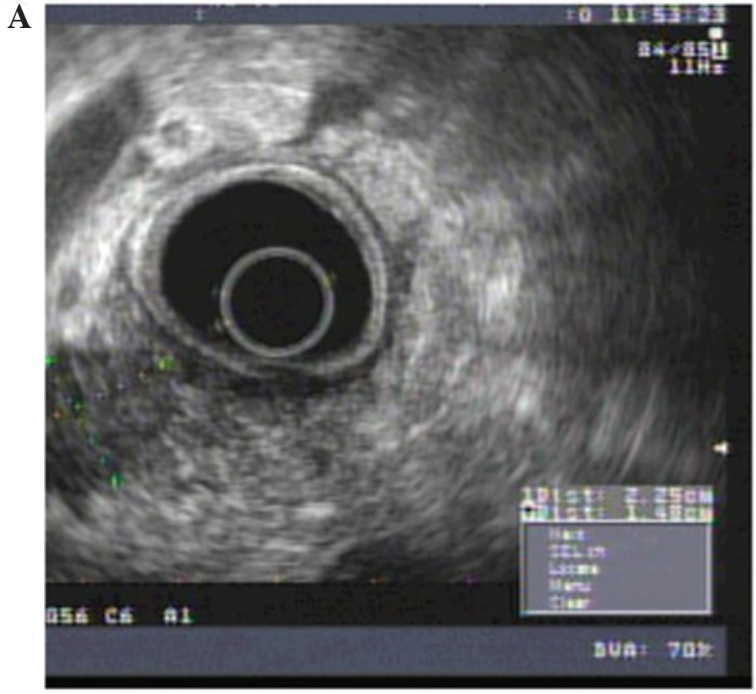

B

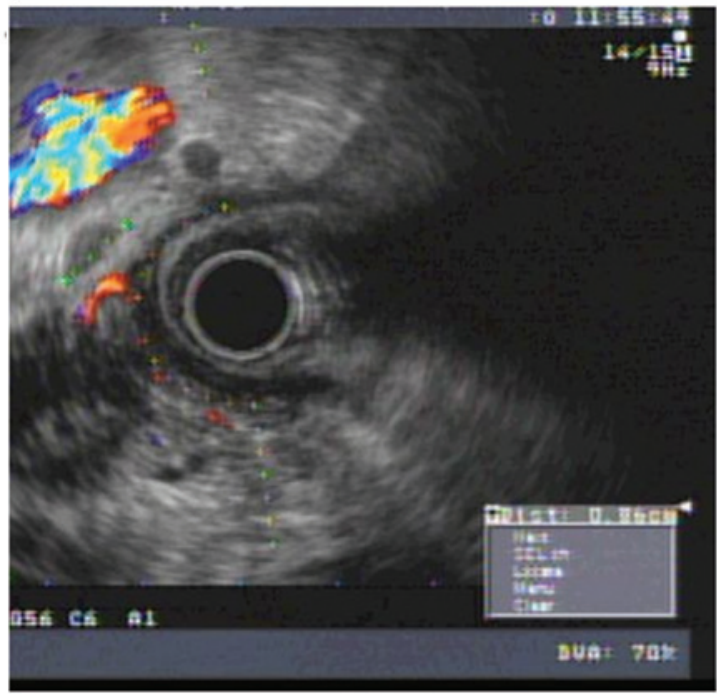

Figure 1. Endoscopic ultrasound (EUS) was suggestive of pancreatic cancer preoperatively because the ultrasonographic features of mass-forming focal chronic pancreatitis (MFP) are similar to those of pancreatic carcinoma and could not be absolutely excluded. Under EUS, the pancreatic body and tail were observed to be significantly narrowed (diameter $<1 \mathrm{~cm}$ ). (A) There was a low echo lesion at the head of pancreas $(2.3 \times 1.5 \mathrm{~cm})$, breaking through the pancreatic envelope, and (B) a $1.1 \mathrm{~cm}$ enlarged lymph node.

In addition to use as a diagnostic technique, EUS-FNA has also been developed as a therapeutic means, such as for

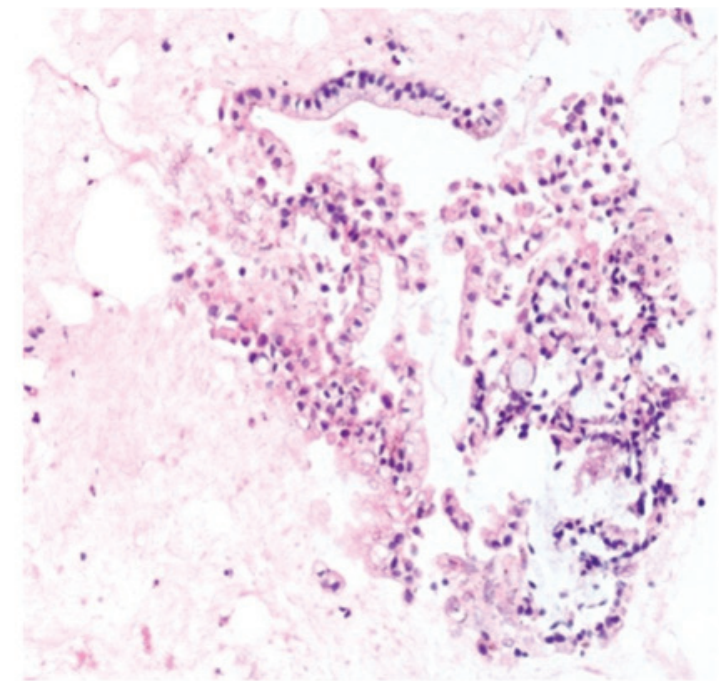

B

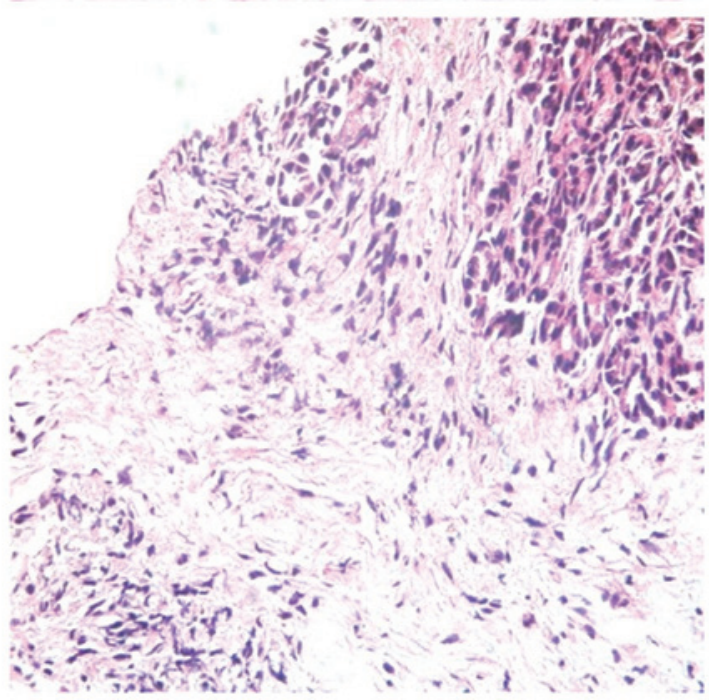

Figure 2. Histological examination of the cells obtained from the fine needle biopsy helped to distinguish between benign and malignant lesions. (A) Endoscopic ultrasound-guided-fine needle aspiration confirmed the pancreatic lesion was mass-forming focal chronic pancreatitis [MFP: hematoxylin and eosin (H\&E) staining, magnification, x200]. (B) Postoperative pathology also confirmed that the pancreatic lesion was MFP (H\&E staining, magnification, $\mathrm{x} 200$ ).

use in celiac plexus neurolysis, pseudocyst drainage, radiation therapy, the delivery of antitumor agents and bile duct drainage $(35,36)$. The total complication rate across the 
reported studies concerning EUS-FNA ranges from 0 to $2.0 \%$ (37-39). With the exception of some instances of mild abdominal discomfort, no complications associated with EUS-FNA were observed in the 150 patients in the present study.

In conclusion, EUS-FNA has emerged as a powerful modality for acquiring cytology results from types of lesion diseases. The results of the present study demonstrated that EUS-FNA provides an incomparable superiority for the investigation of various masses and is able to diagnose suspected neoplastic lesions with a high sensitivity and specificity. Furthermore, it is a safe procedure with low complication rates, although more high-quality, larger-scale and prospective studies are required.

\section{Acknowledgements}

This study was supported in part by the National Natural Science Foundation of China (grant nos. 81000160, 81272656, 30900664, 81470039 and 81170373).

\section{References}

1. Harewood GC and Wiersema MJ: Endosonography-guided fine needle aspiration biopsy in the evaluation of pancreatic masses. Am J Gastroenterol 97: 1386-1391, 2002.

2. Sengupta S, Pal S, Biswas BK, Chakrabarti S, Bose K and Jana S: Fine-needle aspiration cytology of retroperitoneal lesions: A 5-year experience with an emphasis on cytohistological discrepancy. Acta Cytol 58: 138-144, 2014.

3. Han C, Lin R, Liu J, Hou X, Qian W and Ding Z: Endoscopic Ultrasonography-Guided Biopsy for Differentiation of Benign and Malignant Pelvic Lesions: A Systematic Review and Meta-Analysis. Dig Dis Sci 60: 3771-3781, 2015.

4. Vilmann P, Jacobsen GK, Henriksen FW and Hancke S: Endoscopic ultrasonography with guided fine needle aspiration biopsy in pancreatic disease. Gastrointest Endosc 38: 172-173, 1992.

5. Chen J, Yang R, Lu Y, Xia Y and Zhou H: Diagnostic accuracy of endoscopic ultrasound-guided fine-needle aspiration for solid pancreatic lesion: A systematic review. J Cancer Res Clin Oncol 138: 1433-1441, 2012.

6. Cho C, Dewitt J and Al-Haddad M: Echo-endoscopy: New therapeutic frontiers. Minerva Gastroenterol Dietol 57: 139-158, 2011.

7. Krishna NB, LaBundy JL, Saripalli S, Safdar R and Agarwal B: Diagnostic value of EUS-FNA in patients suspected of having pancreatic cancer with a focal lesion on CT scan/MRI but without obstructive jaundice. Pancreas 38: 625-630, 2009.

8. Eloubeidi MA, Tamhane A, Varadarajulu S and Wilcox CM: Frequency of major complications after EUS-guided FNA of solid pancreatic masses: A prospective evaluation. Gastrointest Endosc 63: 622-629, 2006.

9. Beane JD, House MG, Coté GA, DeWitt JM, Al-Haddad M, LeBlanc JK, McHenry L, Sherman S, Schmidt CM, Zyromski NJ, et al: Outcomes after preoperative endoscopic ultrasonography and biopsy in patients undergoing distal pancreatectomy. Surgery 150: 844-853, 2011.

10. Zeppa P, Barra E, Napolitano V, Cozzolino I, Troncone G, Picardi M, De Renzo A, Mainenti PP, Vetrani A and Palombini L: Impact of endoscopic ultrasound-guided fine needle aspiration (EUS-FNA) in lymph nodal and mediastinal lesions: A multicenter experience. Diagn Cytopathol 39: 723-729, 2011.

11. Turner BG, Cizginer S, Agarwal D, Yang J, Pitman MB and Brugge WR: Diagnosis of pancreatic neoplasia with EUS and FNA: A report of accuracy. Gastrointest Endosc 71: 91-98, 2010.

12. Maker AV, Katabi N, Gonen M, DeMatteo RP, D'Angelica MI, Fong Y, Jarnagin WR, Brennan MF and Allen PJ: Pancreatic cyst fluid and serum mucin levels predict dysplasia in intraductal papillary mucinous neoplasms of the pancreas. Ann Surg Oncol 18: 199-206, 2011.
13. Nguyen TQ, Kalade A, Prasad S, Desmond P, Wright G, Hart D, Conron $M$ and Chen RY: Endoscopic ultrasound guided fine needle aspiration (EUS-FNA) of mediastinal lesions. ANZ J Surg 81: 75-78, 2011.

14. Dubravcsik Z, Serényi P, Madacsy L and Szepes A: Endoscopic ultrasound-guided fine needle aspiration cytology in the mediastinum. Orvosi Hetill 154: 338-344, 2013 (In Hungarian).

15. Han C, Lin R, Yu J, Zhang Q, Zhang Y, Liu J, Ding Z and Hou X: A case report of esophageal bronchogenic cyst and review of the literature with an emphasis on endoscopic ultrasonography appearance. Medicine (Baltimore) 95: e3111, 2016.

16. Chen G, Liu S, Zhao Y, Dai M and Zhang T: Diagnostic accuracy of endoscopic ultrasound-guided fine-needle aspiration for pancreatic cancer: A meta-analysis. Pancreatology 13: 298-304, 2013.

17. Puli SR, Bechtold ML, Buxbaum JL and Eloubeidi MA: How good is endoscopic ultrasound-guided fine-needle aspiration in diagnosing the correct etiology for a solid pancreatic mass? A meta-analysis and systematic review. Pancreas 42: 20-26, 2013.

18. Puli SR, Batapati Krishna Reddy J, Bechtold ML, Ibdah JA, Antillon D, Singh S, Olyaee M and Antillon MR: Endoscopic ultrasound: It's accuracy in evaluating mediastinal lymphadenopathy? A meta-analysis and systematic review. World J Gastroenterol 14: 3028-3037, 2008.

19. Korenblit J, Anantharama A, Loren DE, Kowalski TE and Siddiqui AA: The role of endoscopic ultrasound-guided fine needle aspiration (EUS-FNA) for the diagnosis of intra-abdominal lymphadenopathy of unknown origin. J Interv Gastroenterol 2: 172-176, 2012.

20. Anderson B, Singh J and Jafri SF: Tumor seeding following endoscopic ultrasonography-guided fine-needle aspiration of a celiac lymph node. Dig Endosc 25: 344-345, 2013.

21. Huh JW, Kwon SY, Lee JH and Kim HR: Comparison of restaging accuracy of repeat FDG-PET/CT with pelvic MRI after preoperative chemoradiation in patients with rectal cancer. J Cancer Res Clin Oncol 141: 353-359, 2015.

22. Moon JH, Choi HJ and Lee YN: Endoscopic retrograde cholangiopancreatography. Endoscopy 46: 775-778, 2014.

23. Kedia P, Gaidhane $M$ and Kahaleh M: Technical advances in endoscopic ultrasound (EUS)-guided tissue acquisition for pancreatic cancers: How can we get the best results with EUS-guided fine needle aspiration? Clin Endosc 46: 552-562, 2013.

24. Volmar KE, Vollmer RT, Jowell PS, Nelson RC and Xie HB: Pancreatic FNA in 1000 cases: A comparison of imaging modalities. Gastrointest Endosc 61: 854-861, 2005.

25. Wilson JL, Kalade A, Prasad S, Cade R, Thomson B, Banting S, Mackay S, Desmond PV and Chen RY: Diagnosis of solid pancreatic masses by endoscopic ultrasound-guided fine-needle aspiration. Intern Med J 39: 32-37, 2009.

26. Yoshinaga S, Suzuki H, Oda I and Saito Y: Role of endoscopic ultrasound-guided fine needle aspiration (EUS-FNA) for diagnosis of solid pancreatic masses. Dig Endosc 23 (Suppl 1): 29-33, 2011.

27. LeBlanc JK, Ciaccia D, Al-Assi MT, McGrath K, Imperiale T, Tao LC, Vallery S, DeWitt J, Sherman S and Collins E: Optimal number of EUS-guided fine needle passes needed to obtain a correct diagnosis. Gastrointest Endosc 59: 475-481, 2004.

28. Fusaroli P, Spada A, Mancino MG and Caletti G: Contrast harmonic echo-endoscopic ultrasound improves accuracy in diagnosis of solid pancreatic masses. Clin Gastroenterol Hepatol 8: 629-634, e622, 2010.

29. Napoleon B, Alvarez-Sanchez MV, Gincoul R, Pujol B, Lefort C, Lepilliez V, Labadie M, Souquet J, Queneau PE, Scoazec JY, et al: Contrast-enhanced harmonic endoscopic ultrasound in solid lesions of the pancreas: Results of a pilot study. Endoscopy 42: 564-570, 2010 .

30. Sun B, Yang X, Ping B, He Y and Zhang Z: Impact of inconclusive endoscopic ultrasound-guided fine-needle aspiration results in the management and outcome of patients with solid pancreatic masses. Dig Endosc 27: 130-136, 2015.

31. Maleki Z, Erozan Y, Geddes S and Li QK: Endorectal ultrasound-guided fine-needle aspiration: A useful diagnostic tool for perirectal and intraluminal lesions. Acta Cytol 57: 9-18, 2013.

32. Iglesias-Garcia J, Dominguez-Munoz JE, Abdulkader I, Larino-Noia J, Eugenyeva E, Lozano-Leon A and Forteza-Vila J: Influence of on-site cytopathology evaluation on the diagnostic accuracy of endoscopic ultrasound-guided fine needle aspiration (EUS-FNA) of solid pancreatic masses. Am J Gastroenterol 106: 1705-1710, 2011. 
33. Alsohaibani F, Girgis S and Sandha GS: Does onsite cytotechnology evaluation improve the accuracy of endoscopic ultrasound-guided fine-needle aspiration biopsy? Can J Gastroenterol 23: 26-30, 2009.

34. Campisi P, Accinelli G, De Angelis C, Pacchioni D and Bussolati G: On-site evaluation and triage for endoscopic ultrasound-guided fine needle aspiration cytology. The Turin experience. Minerva Med 98: 395-400, 2007 (In Italian).

35. Al-Haddad M and Eloubeidi MA: Interventional EUS for the diagnosis and treatment of locally advanced pancreatic cancer. JOP 11: 1-7, 2010.

36. Widmer JL and Michel K: Endoscopic ultrasound-guided treatment beyond drainage: Hemostasis, anastomosis and others. Clin Endosc 47: 432-439, 2014.
37. Fisher L, Segarajasingam DS, Stewart C, Deboer WB and Yusoff IF: Endoscopic ultrasound guided fine needle aspiration of solid pancreatic lesions: Performance and outcomes. J Gastroenterol Hepatol 24: 90-96, 2009.

38. Möller K, Papanikolaou IS, Toermer T, Delicha EM, Sarbia M, Schenck U, Koch M, Al-Abadi H, Meining A, Schmidt H, et al: EUS-guided FNA of solid pancreatic masses: High yield of 2 passes with combined histologic-cytologic analysis. Gastrointest Endosc 70: 60-69, 2009.

39. Hwang CY, Lee SS, Song TJ, Moon SH, Lee D, Park DH, Seo DW, Lee SK and Kim MH: Endoscopic ultrasound guided fine needle aspiration biopsy in diagnosis of pancreatic and peripancreatic lesions: A single center experience in Korea. Gut Liver 3: 116-121, 2009. 